\title{
Inspeção de boas práticas de fabricação e enumeração de coliformes totais em fábricas de ração para suínos
}

\section{Application of a good manufacturing practices checklist and enumeration of total coliform in swine feed mills}

\author{
Debora da Cruz Payao Pellegrini ${ }^{1 *}$; Daniel dos Santos Paim²; \\ Gustavo Julio Mello Monteiro de Lima ${ }^{3}$; Jalusa Deon Kich ${ }^{3}$; Arlei Coldebella ${ }^{3}$; \\ Marisa Ribeiro de Itapema Cardoso ${ }^{4}$
}

Resumo

Um estudo transversal realizado em quatro fábricas de ração para suínos foi realizado para avaliar o escore obtido no roteiro de inspeção de boas práticas de fabricação da Instrução Normativa 4 (Ministério da Agricultura, Pecuária e Abastecimento) e os níveis de coliformes totais presentes ao longo do processo de produção. A maioria das não conformidades foi encontrada na estrutura física das fábricas. A fábrica $\mathrm{B}$ apresentou o menor número de inconformidades, enquanto as fábricas $\mathrm{A} \mathrm{e}$ D apresentaram o maior número de itens não conformes. Em 38,53\% (489/1269) das amostras havia presença de coliformes totais, porém não houve diferença no número encontrado entre as amostras e fábricas. A regressão logística apontou maior razão de chance (OR) de isolamento de coliformes totais nas áreas de dosagem (OR=9,51, IC 95\%: 4,43-20,41), moagem (OR=7,10; IC 95\%: 3,27-15,40) e em resíduos (OR=6,21; IC 95\%: 3,88-9,95). A fábrica $\mathrm{C}$, apesar de ter obtido o segundo melhor escore no roteiro de inspeção, apresentou a maior chance de presença de coliformes totais $(\mathrm{OR}=2,43$, IC 95\%: $1,68-3,53)$. Não houve associação entre o escore do roteiro de inspeção e a presença de indicadores de higiene em fábricas de ração.

Palavras-chave: Ração animal, Enterobacteriaceae, boas práticas de fabricação (BPF), níveis de contaminação

\footnotetext{
Abstract

A cross-sectional study in four swine feed mills aimed to evaluate the correlation between the score of the inspection checklist defined in the Normative Instruction 4 (IN 4/ Brazilian Ministry of Agriculture, Livestock and Food Supply), and the enumeration of total coliforms throughout the manufacturing process. The most of non-conformities was found in the physical structure of the feed mills. Feed mill B showed the lowest number of unconformities while units A and D had the largest number of nonconformities. In $38.53 \%(489 / 1269)$ of the samples the presence of total coliform was detected, however no significant difference in the bacterial counts was observed between sampling sites and feed mills. The logistic regression pointed higher odds ratio (OR) for total coliforms isolation at dosing $(\mathrm{OR}=9.51$, $95 \% \mathrm{CI}: 4.43$ to 20.41$)$, grinding $(\mathrm{OR}=7.10,95 \% \mathrm{CI}=3.27$ to 15.40$)$ and residues $(\mathrm{OR}=6.21,95 \%$ CI: 3.88 to 9.95 ) In spite of having the second score in the checklist inspection, feed mill $\mathrm{C}$ presented

${ }^{1}$ Prof $^{\mathrm{a}}$ da Universidade Federal do Pampa, UNIPAMPA, Uruguaiana, RS. E-mail deborapellegrini@unipampa.edu.br

${ }^{2}$ Discente da Universidade Federal do Rio Grande do Sul, UFRGS, Porto Alegre, RS. E-mail:daniel_paim@hotmail.com

${ }^{3}$ Pesquisadores da Empresa Brasileira de Pesquisa Agropecuária, Embrapa Suínos e Aves, Concórdia, SC. E-mail: gustavo.lima@ embrapa.br; jalusa.kich@embrapa.br; arlei.coldebella@embrapa.br

${ }^{4}$ Prof ${ }^{\mathrm{a}}$ da UFRGS, Porto Alegre, RS. E-mail: mcardoso@ufrgs.br
}

* Autor para correspondência 
the highest odds for total coliforms isolation $(\mathrm{OR}=2,43$, IC 95\%: 1,68-3,53). The data indicate no association between the score of checklist and the presence of hygienic indicators in feed mills.

Key words: Feed, Enterobacteriaceae, good manufacturing practices (GMP), contamination levels

\section{Introdução}

A carne suína é a proteína animal de maior consumo mundial, demandando uma produção anual de cerca de 115 milhões de toneladas para suprir o mercado. O Brasil ocupa a posição de quarto maior produtor, participando com $3 \%$ da produção e $11 \%$ das exportações mundiais (ABIPECS, 2011). A competitividade nesse mercado depende da qualidade do produto ofertado, a qual inclui a sua inocuidade à saúde do consumidor.

O controle de micro-organismos patogênicos transmitidos por produtos cárneos compreende linhas de ação focadas nas etapas de pré-abate, abate e pós-abate (WHO, 1980). Entre as medidas instituídas no pré-abate, o monitoramento e controle da contaminação da ração assumem grande relevância, por ser a ração uma das principais formas de veiculação de agentes patogênicos para os suínos (EFSA, 2008).

Apesardediversos estudos citaremosingredientes como os principais responsáveis pela introdução de contaminantes na linha de processamento das fábricas, outros fatores como poeira, presença de roedores, umidade e tempo de estoque têm sido considerados capazes de influenciar a inocuidade de um lote de ração (JONES, 2002; COMA, 2003; RICHARDSON, 2008). Em alguns estudos, a quantificação de micro-organismos indicadores, como as enterobactérias e os coliformes totais, foi proposta para verificar a eficácia de processos de descontaminação, avaliar as condições higiênicosanitárias das linhas de produção das fábricas de ração e estimar o risco de contaminação por patógenos (VELDMAN; VAHL; BOORGGREVE, 1995; JONES; RICHARDSON, 2004).

A adoção de programas de Análise de Perigos e Pontos Críticos de Controle (APPCC) e Boas Práticas de Fabricação (BPF) durante a elaboração de dietas nas fábricas de ração são estratégias essenciais para minimizar o risco de contaminação (PRIMM, 1998; PETRI, 2002). No Brasil, a regulamentação e fiscalização de produtos destinados à alimentação animal é responsabilidade do Ministério da Agricultura, Pecuária e Abastecimento (MAPA). Em 2007, entrou em vigor a Instrução Normativa número 4 (IN 4) (BRASIL, 2007), regulamento que define os procedimentos básicos de higiene e de boas práticas de fabricação para alimentos produzidos e industrializados destinados ao consumo animal e propõe um roteiro de inspeção para as fábricas. Desde sua publicação, as fábricas de ração estão em processo de adequação, encontrando-se em diferentes níveis de cumprimento do regulamento. Por outro lado, a situação em relação à presença de indicadores de higiene nas fábricas de ração para suínos é ainda pouco investigada.

Desse modo, o presente estudo foi realizado para avaliar fábricas de ração quanto ao escore obtido na aplicação do roteiro de inspeção e a enumeração de coliformes totais em diversas etapas do processo de produção de dietas para suínos, verificando a associação entre os resultados dos dois instrumentos de avaliação.

\section{Material e Métodos}

Foi realizado um estudo transversal em quatro fábricas de dietas para suínos, pertencentes a diferentes sistemas verticalizados de produção, localizados nas regiões Sul e Sudeste. O fluxograma de produção de cada unidade foi listado e um mínimo de 50 pontos de amostragem para pesquisa de coliformes totais foi definido por fábrica, contemplando as etapas de recebimento, processamento e expedição. Em cada fábrica, foram realizados seis ciclos de amostragem e uma aplicação do roteiro de inspeção de boas práticas 
de fabricação de estabelecimentos fabricantes de produtos destinados à alimentação animal, que consta como anexo da IN 4 (BRASIL, 2007).

As quatro fábricas de ração incluídas no estudo (A, B, C, D) produziam, respectivamente, 16.000, 4.000, 5.000 e 38.000 toneladas de ração mensais. As unidades estavam organizadas nas seguintes áreas: recebimento dos ingredientes a granel ou ensacados, armazenagem em silos externos ou internos, galpões e tanques, moagem, dosagem, mistura, peletização, resfriamento, ensaque do produtofinal e expedição. O recebimento dos ingredientes a granel era realizado em moegas, enquanto os ensacados permaneciam estocados no setor de armazenagem. A distribuição dos ingredientes para os silos internos e externos era realizada por meio de elevadores e transportadores. As fábricas B, C e D produziam rações fareladas e peletizadas, enquanto a fábrica A somente ração farelada. A expedição do produto final era realizada diretamente no interior de caminhões ou após ensaque. Quanto à adoção de programas de qualidade e certificações, a fábrica B seguia as instruções descritas na IN 4 (BRASIL, 2007) e também possuía duas certificações (BPFs avançadas e APPCC) inseridas no programa Gestão do Alimento Seguro (SINDIRAÇÕES, 2006). As fábricas A, C e D estavam em fase de adequação e estruturação dos itens propostos na IN 4 (BRASIL, 2007).

O roteiro de inspeção foi aplicado pelo mesmo operador, na última visita realizada em cada fábrica incluída no estudo. O escore de classificação do estabelecimento foi obtido de acordo com o atendimento dos itens imprescindíveis e necessários, conforme a média ponderada descrita no Anexo II da IN4. De acordo com a pontuação alcançada, os estabelecimentos foram classificados em grupos (BRASIL, 2009): Grupo 1 (81 a 100 pontos); Grupos 2 (61 a 80); Grupo 3 (41 a 60); e Grupo 4 (0 a 40).

Para a avaliação de Coliformes Totais foram colhidas amostras de ingredientes, produto final e nos equipamentos. Cada amostra foi composta por 10 alíquotas, de cerca de 10 gramas, colhidas individualmente para aumentar a representatividade (RICHARDSON, 2008), e acondicionadas em um mesmo saco plástico estéril. As amostras de ingredientes não ensacados foram colhidas diretamente na moega, através das janelas de inspeção ou na extremidade superior do equipamento. Os ingredientes ensacados foram amostrados, individualmente, em uma embalagem aberta no momento da colheita da amostra. Nos equipamentos (silos, transportadores, moinhos, balanças, peletizadoras e resfriadores), a colheita de amostra foi realizada através do óculo de inspeção ou após a abertura do equipamento. Nesse caso, foi colhida a poeira depositada no interior dos equipamentos. Além disso, foram amostradas a poeira depositada no chão da fábrica (varredura) e as incrustações encontradas no interior dos equipamentos (resíduos). Durante a amostragem, o operador utilizava luvas estéreis, que eram trocadas antes de cada colheita.

As amostras, transportadas em temperatura ambiente ao Setor de Medicina Veterinária Preventiva da UFRGS, foram homogeneizadas e 25 $\mathrm{g}$ foram retirados e adicionados á $225 \mathrm{ml}$ de água peptonada tamponada $1 \%$. A partir dessa diluição $\left(10^{-1}\right)$, foram realizadas diluições decimais seriadas até $10^{-6}$. Alíquotas de $1 \mathrm{~mL}$ de cada diluição foram semeadas, em duplicata, em Agar Bile Violeta Vermelho Neutro (VRBA, Oxoid) pela técnica de plaqueamento em profundidade. Após incubação á $37^{\circ} \mathrm{C}$ por $48 \mathrm{~h}$, o número de colônias características (rosas rodeadas por precipitado de cor púrpura) foi multiplicado pelo inverso da diluição de contagem e expressa em número de unidades formadoras de colônia por grama de amostra (UFC. g $^{-1}$ ) (SILVA et al., 2010).

Para permitir a comparação entre fábricas, as amostras foram estratificadas nos seguintes grupos: ingredientes ensacados, ingredientes a granel, transportadores, extrusão, moagem, dosagem, mistura, peletização, produto final, 
varredura e resíduo. A quantificação de coliformes totais, expressa em UFC. $\mathrm{g}^{-1}$, foi convertida em escala logarítmica, sendo a comparação entre grupos de amostras e fábricas, quanto ao grau de contaminação por coliformes totais, realizada pelo teste não paramétrico Kruskal-Wallis. Para verificar quais áreas e fábricas apresentaram maior probabilidade de isolamento de coliformes totais, primeiramente foi realizada uma análise univariada através do teste de qui-quadrado $\left(\chi^{2}\right)$, sendo as variáveis significativas $(\mathrm{p}<0,25)$ incluídas no modelo de regressão logística para estimação das razões de chance (Odds Ratio - OR) para presença de coliformes totais. A estratégia escolhida para elaboração do modelo foi o método "enter", sendo a fábrica $\mathrm{B}$ e o grupo de amostras "ingredientes ensacado" selecionados como referência. Para avaliar a aderência do modelo, comparando os dados observados e os previstos, foram utilizadas a estatística de verossimilhança-log e avaliação dos resíduos. Todos os parâmetros foram estimados em intervalos com 95\% de confiança. As análises foram realizadas no programa SPSS versão 18 (2010).

\section{Resultados e Discussão}

A análise dos 128 itens considerados necessários no roteiro de inspeção da IN4 (Tab.1) demonstrou que aqueles relativos ao abastecimento de água, controle de pragas, manutenção de equipamentos e programas de rastreabilidade foram cumpridos por todas as unidades avaliadas. Em todos os estabelecimentos, a maior dificuldade em cumprir a legislação foi relacionada à estrutura da área interna e externa das fábricas. Os maiores problemas apontados no roteiro de inspeção compreenderam itens referentes à construção, estrutura física e área da unidade de produção (presença de materiais em desuso, conservação de pisos, paredes, janelas, iluminação e ventilação), havendo maior adequação quanto à realização dos Procedimentos Operacionais Padrões (POP). No processo de adequação à legislação em que as fábricas se encontravam, espera-se que as alterações sejam iniciadas pelos programas de qualidade e alteração de processo. Por outro lado, as modificações na estrutura física demandam investimentos e obras executadas na fábrica, que, na maioria das vezes, tem impacto na própria capacidade de produção da unidade. Por conta disto, as adequações de estrutura física acabam sendo alcançadas em última instância.

A fábrica $\mathrm{B}$ apresentou $\mathrm{o}$ menor número de inconformidades, com apenas três itens em desacordo com a legislação, correspondentes à área interna, instalações sanitárias/vestiários para funcionários e equipamentos/utensílios. As fábricas A e D apresentaram o maior número de itens não conformes em ambos os grupos, sendo os itens relacionados à estrutura da área interna e limpeza e higienização de equipamentos os de maior frequência de inconformidades. Entre os 29 itens classificados como imprescindíveis no roteiro de inspeção, oito não foram cumpridos por pelo menos uma das fábricas (Tab. 2). A fábrica B apresentou todos os itens em conformidade, ao passo que as fábricas $\mathrm{A}$ e $\mathrm{D}$ não cumpriram os oito itens. A fábrica $\mathrm{C}$ apresentou três itens não conformes, relacionados à limpeza de piso e parede, recepção e armazenamento de matérias-primas. Os itens imprescindíveis em desacordo eram relacionados á aspectos de higiene e fluxo de processo, os quais podem contribuir para a presença residual de microorganismos na fábrica e contaminação cruzada da ração, como relatado em diversos estudos (VAN SCHOTHORST; OOSTERROM, 1984; JONES; RICHARDSON, 2004; TORRES et al., 2011). 
Tabela 1. Número de itens não conformes entre o total de itens classificados como necessários nos dois grupos que compõem o Roteiro de Inspeção da Instrução Normativa (IN4) de 23 de fevereiro de 2007, em quatro fábricas de ração para suínos (A, B, C, D).

\section{Grupo/Item}

\section{Estrutura}

Área externa

Área interna

Instalações sanitárias e vestiários para os funcionários

Lavatórios para a área de produção

Instalações

Equipamentos e utensílios

Programa de treinamento de funcionários

Controle do Processo de Produção, Armazenamento e

Expedição

\section{Procedimentos Operacionais Padrões}

Qualificação de fornecedores e controle de matérias-primas, ingredientes e embalagens

Limpeza/higienização de instalações, equipamentos e utensílios

Higiene e saúde do pessoal

Potabilidade da água e higienização do reservatório

Prevenção de contaminação cruzada

Manutenção e calibração de equipamentos e instrumentos

Controle integrado de pragas

Controle de resíduos e efluentes

Rastreabilidade e recolhimento de produtos

Total

Fonte: Elaboração dos autores.

Tabela 2. Itens classificados como imprescindíveis no Roteiro de Inspeção da Instrução Normativa 4 (IN 4) de 23 de fevereiro de 2007 que apresentaram inconformidade em pelo menos uma das fábricas de ração (A, B, C, D) avaliadas.

\begin{tabular}{|c|c|c|c|c|}
\hline \multirow{2}{*}{ Item } & \multicolumn{4}{|c|}{ Fábrica } \\
\hline & A & $\mathbf{B}$ & $\mathbf{C}$ & $\mathbf{D}$ \\
\hline Pisos e paredes em bom estado de limpeza e conservação & $\mathrm{X}$ & & $\mathrm{X}$ & $\mathrm{X}$ \\
\hline Área isolada para armazenar aditivos e medicamentos & $\mathrm{X}$ & & & $\mathrm{X}$ \\
\hline $\begin{array}{l}\text { Recepção da matéria-prima ou ingredientes em local coberto ou em sistema } \\
\text { fechado }\end{array}$ & $X$ & & $\mathrm{X}$ & X \\
\hline $\begin{array}{l}\text { Matérias-primas e ingredientes armazenados em área específica e em } \\
\text { condições apropriadas }\end{array}$ & $\mathrm{X}$ & & $\mathrm{X}$ & $\mathrm{X}$ \\
\hline $\begin{array}{l}\text { Produtos de limpeza ou higienização identificados e guardados em local } \\
\text { adequado }\end{array}$ & $\mathrm{X}$ & & & $\mathrm{X}$ \\
\hline $\begin{array}{l}\text { Asseio corporal dos funcionários, mãos limpas, unhas curtas, sem esmalte, } \\
\text { sem adornos e manipuladores com barbas, bigodes e cabelos protegidos. }\end{array}$ & $\mathrm{X}$ & & & $\mathrm{X}$ \\
\hline $\begin{array}{l}\text { Controle de sequência da elaboração dos produtos visando evitar } \\
\text { contaminação }\end{array}$ & $\mathrm{X}$ & & & $\mathrm{X}$ \\
\hline $\begin{array}{l}\text { Manipulação de aditivos e medicamentos realizada de forma que evite a } \\
\text { contaminação cruzada. }\end{array}$ & $\mathrm{X}$ & & & $\mathrm{X}$ \\
\hline
\end{tabular}

Fonte: Elaboração dos autores. 
A partir da avaliação dos itens do roteiro de inspeção, foram atribuídos os seguintes escores para as fábricas: 94,62 (B); 81,51 (C); 67,37 (A) e 67,11 (D). As fábricas B e C foram classificadas no Grupo 1 e as fábricas A e D no Grupo 2, de acordo com o previsto na Instrução Normativa 15 do MAPA (BRASIL, 2009). Segundo essa normativa, estabelecimentos exportadores e fabricantes de produtos com medicamentos devem pertencer ao Grupo 1. Os estabelecimentos classificados como Grupo 2 e 3 recebem prazos para adequação, enquanto aqueles classificados no Grupo 4 sofrem interdição temporária. Dessa forma, observa-se que nenhuma das fábricas estudadas apresentava situação crítica em relação à estrutura e boas práticas de fabricação, enquanto a fábrica $\mathrm{B}$, que já contava com diversos certificados de qualidade, alcançou o melhor escore também no roteiro de inspeção da IN4.

No total, foram analisadas 1.269 amostras colhidas em diversas etapas da elaboração da ração, das quais 489 (38,53\%) tiveram presença de coliformes totais. As contagens médias encontradas, expressas em $\log _{10} \mathrm{~g}^{-1}$, considerando todas as amostras analisadas por fábrica, foram: A: 0,97 (IC 95\%: 0,81-1,13); B: 0,78 (IC 95\%: 0,61-0,94); C: 1,32 (IC 95\%: 1,16-1,49) e D: 0,91 (IC 95\%: 0,75$1,06)$. Houve elevada variabilidade no número de coliformes totais nas amostras colhidas nas quatro fábricas (Tab. 3), sem diferença significativa entre os grupos de amostras e entre as fábricas $(p=0,174)$. Jones e Richardson (2004) encontraram médias de enterobactérias de $2,56 \log _{10} \cdot \mathrm{g}^{-1}$ em ingrediente (farinha de soja), de 4,98 até 5,17 $\log _{10} \cdot \mathrm{g}^{-1} \mathrm{em}$ poeira recolhida no misturador e 5,26 $\log _{10} . \mathrm{g}^{-1} \mathrm{em}$ amostras de ração pronta, em três fábricas que processavam entre 100.000 e 400.000 toneladas de ração por ano. Observa-se que as médias encontradas no presente estudo foram bem inferiores às relatadas pelos autores, o que pode ser interpretado como uma evidência de que as fábricas amostradas estavam em boas condições de higiene. Por outro lado, uma comparação direta dos resultados não é possível, pois no presente estudo foi conduzida a enumeração de coliformes totais, ou seja, um subgrupo de fermentadoras de lactose dentro das enterobactérias (SILVA et al., 2010). Mesmo considerando essa limitação, é possível inferir que a frequência de amostras positivas e o número de coliformes totais não foram elevados. Valores de referência de enterobactérias ou de coliformes totais, para classificação das fábricas, ainda não foram estabelecidos, porém a quantificação de indicadores tem sido mencionada como associada à presença de outros micro-organismos, como Salmonella, em ração (VAN SCHOTHORST; OOSTERROM, 1984; VELDMAN; VAHL; BOORGGREVE, 1995; JONES; RICHARDSON, 2004). Programas de monitoramento de Salmonella (PDV, 2002; EFSA, 2008) têm proposto a quantificação de enterobactérias ou de coliformes como uma ferramenta de avaliação de risco de contaminação, porém alertam que essa relação precisa ser mais bem estudada.

Ao considerar a detecção (presença/ausência) de coliformes totais, as amostras do grupo dosagem, moagem e resíduos apresentaram as maiores frequências de isolamento, enquanto os grupos ingredientes e produto final apresentaram o menor número de amostras positivas (Tab. 4). Entre as amostras que apresentaram maiores frequências de isolamento de coliformes totais, resíduos e poeira já haviam sido mencionadas em outros estudos (JONES, 2002; JONES; RICHARDSON, 2004; TORRES et al., 2011). Nas fábricas estudadas, constatou-se a presença disseminada de poeira e incrustações em equipamentos, demonstrando a dificuldade de seu controle durante o processo. A poeira produzida durante a fabricação de rações tende a permanecer em suspensão, depositando-se, posteriormente, no interior dos equipamentos e nas instalações. A aceleração necessária para moagem dos grãos nos moinhos favorece a produção de calor, que contribui para a condensação de umidade e formação de incrustações. Da mesma forma, os transportadores, ou elevadores, também 
contribuem para o aumento da temperatura ao longo do processo de produção, além de favorecerem a dispersão de poeira e a ocorrência de contaminação cruzada (JONES, 2002). A utilização de filtros em equipamentos com elevada capacidade de produção e acúmulo de poeira pode ser uma alternativa para a retenção de partículas finas em suspensão (STARK; JONES, 2010), entretanto a troca dos filtros precisa ser realizada frequentemente, de acordo com a saturação, para que a medida seja eficaz.

Tabela 3. Número médio de coliformes totais (log UFC.g- $\left.{ }^{1}\right)$ em amostras positivas colhidas em diferentes áreas de processamento de quatro fábricas de ração para suínos (A, B, C, D).

\begin{tabular}{lcccc}
\hline & \multicolumn{4}{c}{ Log UFC.g- ${ }^{1}{ }^{1}$ médio de Coliformes Totais (Desvio Padrão) } \\
\hline \multicolumn{1}{c}{ Amostra } & $\mathbf{A}$ & $\mathbf{B}$ & $\mathbf{C}$ & D \\
\hline Ingredientes ensacados & 0,00 & $1,86(0,36)$ & $2,45(0,68)$ & 0,00 \\
Ingredientes a granel & $1,86(0,81)$ & $1,98(0,51)$ & $2,30(1,16)$ & $2,13(0,57)$ \\
Produto final & $1,09(0,38)$ & 0,00 & $2,08(0,32)$ & $1,76(0,06)$ \\
Transportador & $2,09(1,01)$ & $2,42(0,87)$ & $2,31(0,77)$ & $2,68(0,97)$ \\
Extrusão & - & - & $3,02(1,72)$ & - \\
Dosagem & $2,64(0,69)$ & $3,82(1,94)$ & $2,66(0,80)$ & $2,59(0,84)$ \\
Moagem & $2,68(1,40)$ & $2,38(0,41)$ & $3,21(1,45)$ & $3,11(1,23)$ \\
Mistura & $1,96(0,64)$ & 0,00 & $1,99(0,53)$ & $2,90(0,93)$ \\
Peletização & - & $1,99(0,83)$ & $2,10(0,98)$ & $2,64(1,11)$ \\
Varredura & $1,56(0,55)$ & $1,55(0,30)$ & $2,41(0,79)$ & $3,08(0,95)$ \\
Resíduos & $2,70(1,33)$ & $3,61(1,24)$ & $3,02(0,95)$ & $3,45(1,39)$ \\
\hline
\end{tabular}

Fonte: Elaboração dos autores.

Tabela 4. Frequência de amostras positivas para coliformes totais em quatro fábricas de ração para suínos (A, B, C, D), de acordo com o tipo de amostra analisada.

\begin{tabular}{|c|c|c|c|c|c|}
\hline \multirow{2}{*}{ Amostra analisada } & \multicolumn{4}{|c|}{ Positivos/Total } & \multirow{2}{*}{ Total } \\
\hline & $\mathbf{A}$ & B & $\mathbf{C}$ & D & \\
\hline Ingredientes ensacados & $0 / 9$ & $3 / 26$ & $5 / 11$ & $0 / 14$ & $8 / 60(13,33 \%)$ \\
\hline Ingredientes a granel & $14 / 96$ & $26 / 100$ & $17 / 82$ & $16 / 106$ & $73 / 384(19,01 \%)$ \\
\hline Produto final & $6 / 23$ & $0 / 24$ & $5 / 12$ & $2 / 21$ & $13 / 80(16,25 \%)$ \\
\hline Transportador & $18 / 48$ & $18 / 35$ & $45 / 54$ & $6 / 27$ & $87 / 164(53,05 \%)$ \\
\hline Extrusão & & & $10 / 24$ & & $10 / 24(41,67 \%)$ \\
\hline Dosagem & $5 / 6$ & $13 / 21$ & $10 / 12$ & $4 / 5$ & $32 / 44(72,73 \%)$ \\
\hline Moagem & $7 / 12$ & $6 / 6$ & $5 / 6$ & $6 / 13$ & $24 / 37(64,86 \%)$ \\
\hline Mistura & $3 / 6$ & $0 / 10$ & $11 / 12$ & $10 / 17$ & $24 / 45(53,33 \%)$ \\
\hline Peletização & & $7 / 30$ & $8 / 24$ & $10 / 43$ & 25/97 (25,77\%) \\
\hline Varredura & $6 / 24$ & $2 / 18$ & $14 / 17$ & $36 / 65$ & $58 / 124(46,77 \%)$ \\
\hline Resíduos & 70/93 & $12 / 19$ & $32 / 54$ & $21 / 44$ & $135 / 210(64,29 \%)$ \\
\hline $\begin{array}{c}\text { Total } \\
(\%)\end{array}$ & $\begin{array}{l}129 / 317 \\
(40,7 \%) \\
\end{array}$ & $\begin{array}{c}87 / 289 \\
(30,1 \%) \\
\end{array}$ & $\begin{array}{l}162 / 308 \\
(52,6 \%) \\
\end{array}$ & $\begin{array}{l}111 / 355 \\
(31,3 \%) \\
\end{array}$ & $\begin{array}{l}489 / 1269 \\
(38,53 \%) \\
\end{array}$ \\
\hline
\end{tabular}

Fonte: Elaboração dos autores.

Como os processos extrusão e peletização não os resultados referentes á esse grupo de amostras eram realizados em todas as fábricas analisadas, foram excluídos da análise estatística. No 
modelo de regressão logística, considerando como variável dependente a presença de coliformes totais (Tab. 5), foram significativas as seguintes variáveis: transportador, dosagem, moagem, mistura, varredura, resíduos e fábrica
C. As estatísticas residuais indicaram uma boa adequação do modelo, com distância de Cook e DFBeta das variáveis previsoras apresentando valores inferiores a 1 e resíduos padronizados abaixo de $\pm 2,5$.

Tabela 5. Razão de Chances (Odds ratio - OR), Intervalo de Confiança (IC 95\%) e valor de P de isolamento de coliformes totais em amostras colhidas em fábricas de ração de suínos obtidos no modelo de regressão logística considerando a fábrica $\mathrm{B}$ e os ingredientes ensacados como referência.

\begin{tabular}{cccc}
\hline Amostra & OR & IC 95\% & P \\
\hline Ingredientes a granel & 0,81 & $0,53-1,26$ & 0,357 \\
Produto final & 0,71 & $0,35-1,43$ & 0,341 \\
Transportador & 3,67 & $2,28-5,89$ & 0,000 \\
Dosagem & 9,51 & $4,43-20,41$ & 0,000 \\
Moagem & 7,10 & $3,27-15,40$ & 0,000 \\
Mistura & 4,10 & $2,04-8,17$ & 0,000 \\
Varredura & 3,50 & $2,10-5,84$ & 0,000 \\
Resíduos & 6,21 & $3,88-9,95$ & 0,000 \\
Fábrica C & 2,43 & $1,68-3,53$ & 0,000 \\
Fábrica D & 0,92 & $0,63-1,35$ & 0,682 \\
Fábrica A & 1,14 & $0,77-1,67$ & 0,514 \\
\hline
\end{tabular}

Fonte: Elaboração dos autores.

A poeira depositada em equipamentos da área de dosagem (OR 9,51) e moagem (OR 7,10) e os resíduos depositados nos equipamentos em geral (OR 6,21) apresentaram a maior razão de chance de isolamento de coliformes totais, demonstrando que são pontos críticos para a presença desses indicadores e, possivelmente, de micro-organismos patogênicos. Os equipamentos das fábricas são caracterizados pela dificuldade de acesso, normalmente sem a existência de janelas de inspeção, o que dificulta a realização de procedimentos de limpeza e higienização. Além disso, a impossibilidade de empregar água na limpeza dos equipamentos implica em processo menos eficaz, dependente da remoção mecânica de resíduos e passagem de produtos químicos secos na linha de processamento. A aplicação de procedimentos de controle implantados em programa de APPCC e a realização de tratamentos físico e/ ou químico auxiliam na prevenção da disseminação da contaminação microbiana para áreas limpas destinadas ao acondicionamento de produto final, o que pode ser observado no presente estudo pelo fato de que a ração pronta não apresentou maior razão de chance de isolamento de coliformes totais em relação aos ingredientes. A temperatura aplicada no processo de peletização é um fator importante para o controle de micro-organismos, sendo estimado que haja a redução de $99 \%$ da contagem total de bactérias presentes na ração após essa etapa (EFSA, 2008). Entretanto, outras variáveis como o desenho da fábrica, a poeira e o contato com o ambiente externo podem influenciar na sua recontaminação (WIERUP; HÄGGBLOM, 2010).

A fábrica $B$ apresentou o melhor escore no roteiro de inspeção, a menor frequência de isolamento de coliformes totais em suas dependências e foi a única a apresentar todas as amostras de produto final sem isolamento de coliformes totais. Nesse caso, o escore obtido na inspeção de BPF esteve de acordo com a avaliação dos indicadores de higiene. 
Ao contrário, a fábrica $\mathrm{C}$, apesar de ter obtido o segundo maior escore no roteiro de inspeção, permaneceu no modelo de regressão logística como a fábrica com maior risco de isolamento de coliformes totais. Dentre todas as unidades avaliadas, a fábrica $\mathrm{C}$ caracterizava-se pela estrutura física e fluxo de produção mais complexos, o que provavelmente favorecia a formação e manutenção de poeira na fábrica. Este resultado leva à hipótese de que o roteiro de inspeção é ideal para avaliar $\mathrm{BPF}$, enquanto que a quantificação de coliformes totais reflete o grau de contaminação microbiana dos equipamentos em contato com a ração, estando associado a diversos outros fatores relacionados à limpeza e estrutura da unidade de produção.

A proposta do MAPA ao instituir a IN4 foi regulamentar as condições higiênico-sanitárias e BPF preconizadas para estabelecimentos fabricantes de produtos destinados à alimentação animal, e encontrou no roteiro de inspeção uma maneira de avaliar a adoção de programas de qualidade nas unidades de produção. Pelos resultados obtidos, verifica-se que o roteiro foi capaz de avaliar a implantação de BPF ao longo do processo de produção, entretanto constatou-se que a classificação obtida pela fábrica não esteve associada com a presença de indicadores de higiene nas instalações e equipamentos. Sendo assim, verifica-se que mesmo cumprindo a maioria dos itens imprescindíveis e necessários do roteiro de inspeção, é recomendável que as fábricas incluam o monitoramento de indicadores microbiológicos como parte dos protocolos de controle da contaminação da ração elaborada.

\section{Conclusões}

O estudo demonstrou que não há associação entre o escore obtido no roteiro de inspeção da IN4 e os níveis de indicadores de higiene em equipamentos utilizados na elaboração de dietas para suínos em fábricas de ração. Os equipamentos empregados na dosagem e moagem e os resíduos presentes na superfície de equipamentos são os mais críticos para a presença de contaminação microbiana. As fábricas devem buscar a implantação de programas de qualidade, monitoramento e controle microbiológico ao longo da linha de produção paralelamente à adequação à legislação vigente, visando à inocuidade dos alimentos produzidos.

\section{Agradecimentos}

Este estudo teve financiamento da Embrapa Suínos e Aves (Macroprograma II projeto $\mathrm{n}^{\circ}$ 02.06.06.004.00.00) e auxílio do Conselho Nacional de Pesquisa (D.C.P.Pellegrini - bolsa de Doutorado, D.S.Paim - bolsa de Iniciação Científica).

\section{Referências}

ASSOCIAÇÃO BRASILEIRA INDÚSTRIA PRODUTORA E EXPORTADORA DE CARNE SUÍNA - ABIPECS. Relatório de atividades: exportações brasileiras de carne suína 2010/2011. São Paulo: Abipecs. Disponível em: <http://www.abipecs.org.br>. Acesso em: 12 fev. 2011.

BRASIL. Instrução Normativa ${ }^{\circ} 4$, de 23 de fevereiro de 2007. Aprova o Regulamento Técnico sobre as Condições Higiênico-Sanitárias e de boas práticas de fabricação para estabelecimentos fabricantes de produtos destinados à Alimentação Animal e o Roteiro de Inspeção. Diário Oficial [da] República Federativa do Brasil, Poder Executivo, Brasília, DF, 01 mar. 2007. Seção 1, p. 5.

Instrução Normativa $n^{\circ} 15$, de 26 de maio de 2009. Regulamenta o registro dos estabelecimentos e dos produtos destinados à alimentação animal. Diário Oficial [da] República Federativa do Brasil, Poder Executivo, Brasília, DF, 28 maio, 2009. Seção 1, p. 1.

COMA, J. Salmonella control in pork: effect of animal nutrition and feeding. Pig News and Information, CABI:Wallingford, v. 24, n. 2, p. 49-62, 2003.

EUROPEAN FOOD SAFETY AUTHORITY - EFSA. Microbiological risk assessment in feedingstuff for foodproducing animals. The EFSA Journal, Parma, n. 720, p. 1-84, 2008.

JONES, F. T. Feed mills APPCC and pathogens reduction strategies. In: MULTI-STATE POULTRY MEETING, 2002. Proceedings... [S.1: s.n.], 2002. p. 1-9. Disponível em: $<$ http://ag.ansc.purdue.edu/poultry/multistate/Multi- 
State\%20Poultry\%20Meeting\%20Proceedings\%20FJ. pdf $>$. Acesso em: 12 jan. 2011.

JONES, F. T.; RICHARDSON, K. E. Salmonella in commercially manufactured feeds. Poultry Science, Champaign, v. 83, n. 3, p. 384-391, 2004.

PRODUCTSCHAP DIERVOEDER - PDV. Programme monitoring salmonella in the animal feed sector. Amsterdam, NL, 2002.39 p.

PETRI, A. Aspects of quality assurance in European feed production. Degussa AG. Concórdia: Embrapa Suínos e Aves, 2002. 57 p. (Relatório PAT 2002).

PRIMM, N. D. Field experiences with the control of Salmonella e introduction into turkey flocks via contaminated feeds. Western Poultry Conference Proceedings, Raleigh, v. 47, p. 27-29, 1998.

RICHARDSON, K. Comprendiendo la contaminación microbiana en el alimento. World Poultry, Doetinchem, v. 26, n. 4 , p. $12-15,2008$.

SILVA, N.; JUNQUEIRA, V. C. A.; SILVEIRA, N. F. A.; TANIWAKI, M. H.; SANTOS, R. F. S.; GOMES, R. A. R. Manual de métodos de análise microbiológica de alimentos e água. 4. ed. São Paulo: Varela, 2010. 623 p.

SINDICATO NACIONAL DA INDÚSTRIA DE ALIMENTAÇÃO ANIMAL - SINDIRAÇÕES. Manual feed \& food safety. Gestão do alimento seguro. Versão 3. São Paulo: Sindirações, out. 2006. Disponível em: $<$ http://www.sindiracoes.org.br $>$. Acesso em: 05 abr. 2010.
STARK, C. R.; JONES, F. T. Quality assurance program in feed manufacturing. Feedstuffs, Bloomington, p. 6267, 16 sept. 2010.

TORRES, G. J.; PIQUER, F. J.; ALGARRA, L.; FRUTOS, C.; SOBRINO, O. J. The prevalence of Salmonella enterica in Spanish feed mills and potential feed-related risk factors for contamination. Preventive Veterinary Medicine, Colorado, v. 98, n. 2-3, p. 81-7, 2011.

VAN SCHOTHORST, M.; OOSTERROM, J. Enterobacteriaceae as indicators of good manufacturing practices in rendering plants. Antonie Van Leeuwenhoek, Netherlands, v. 50, n. 1, p. 1-6, 1984.

VELDMAN, A.; VAHL, H. A.; BOORGGREVE, G. J. A survey of the incidence of Salmonella species and Enterobacteriaceae in poultry feeds and feed components. Veterinary Record, London, v. 136, n. 7, p. 169-172, 1995.

WORLD HEALTH ORGANIZATION - WHO. Report of the WHO/WAVFH round table conference on the present status of the salmonella problem (Prevention and Control). Bilthoven: Netherlands, WHO/VPH/81.27, 1980. $17 \mathrm{p}$.

WIERUP, M.; HÄGGBLOM, P. An assessment of soybeans and other vegetable proteins as source of Salmonella contamination in pig production. Acta Veterinary Scandinavia, Copenhagen, v. 52, n. 1, p. 1-9, 2010. 